\title{
Psicologia na Escola: Construção de um horizonte libertador para o desenvolvimento de crianças e jovens
}

\section{Psychology in the School: Building a liberating horizon for the development of children and young people}

\section{Psicología en la Escuela: Construcción de un horizonte liberador para el desarrollo de niños y jóvenes}

\section{Raquel Souza Lobo Guzzo*}

Pontifícia Universidade Católica de Campinas - PUC-Campinas, Campinas, São Paulo, Brasil

\section{Flávia de Mendonça Ribeiro**}

Pontifícia Universidade Católica de Campinas - PUC-Campinas, Campinas, São Paulo, Brasil

\section{RESUMO}

Esse artigo pretende apresentar um breve ensaio sobre a relação entre Psicologia e Educação, a partir de Martín-Baró e Paulo Freire, no Brasil, como uma referência de rompimento com o modelo tradicional predominante para a área, ao mesmo tempo que pretende discutir a importância da formação crítica em Psicologia, em especial no campo educativo e as demandas e desafios a serem enfrentados no plano técnico e político na inserção de psicólogos na rede educacional pública.

Palavras-chave: psicologia escolar, psicologia da libertação, psicologia crítica.

\begin{abstract}
This article intends to present a brief essay about the relation between Psychology and Education, starting from Martín-Baró and Paulo Freire, in Brazil, as a reference of rupture with the traditional model predominant for the area, at the same time that it intends to discuss the importance of the critical education in Psychology, especially in the educational field and the demands and challenges to be faced in the technical and political plan in the insertion of psychologists into the public educational network.

Keywords: school psychology, liberation psychology, critical psychology.

\section{RESUMEN}

Este artículo pretende presentar un breve ensayo sobre la relación entre Psicología y Educación, a partir de Martín-Baró y Paulo Freire, en Brasil, como una referencia de rompimiento con el modelo tradicional predominante para el área, al mismo tiempo que pretende discutir la importancia de la formación crítica en Psicología, en especial en el campo educativo y las
\end{abstract}


demandas y desafíos a ser enfrentados en el plano técnico y político en la inserción de psicólogos en la red educativa pública.

Palabras clave: psicología escolar, psicología de la liberación, psicología crítica.

\section{Alguns apontamentos históricos sobre a relação entre Psicologia e Educação}

Contar a história da relação entre a Psicologia e Educação é uma imensa tarefa que não é objetivo desse trabalho. Mas é preciso, em uma tentativa de síntese, trazer ao cenário dessa apresentação, alguns pontos importantes e necessários ao entendimento dos rumos que essas duas áreas do conhecimento e de profissão assumiram na sociedade capitalista, especialmente no Brasil de hoje.

No início dos anos 1990, escrevemos um texto (Guzzo \& Almeida, 1992) para tentarmos aproximar um consenso de que uma das primeiras contribuições da Psicologia foi ao processo de desenvolvimento de crianças e adolescentes em instituições educativas. Nessa época, com a promulgação do Estatuto da Criança e Adolescente no Brasil ${ }^{1}$, a escola passou a ser considerada um lugar de possibilidades para o desenvolvimento das crianças e esforços deveriam ser empreendidos para que profissionais de Psicologia pudessem acompanhar de perto esse processo. Até aquele momento, a Psicologia estava bem longe das escolas públicas, mesmo com os indicativos formulados em diferentes legislações relacionadas à Educação (Brasil, 2015), de que o desenvolvimento integral das crianças e adolescentes era objetivo da educação pública, incluindo aí o desenvolvimento psicológico.

Parker $(2007,2009)$ em sua leitura crítica da história da Psicologia argumenta que, com o aparecimento de uma nova sociedade no início do século dezenove, era preciso o surgimento de uma nova ciência que desse conta de entender, explicar e controlar o comportamento das pessoas em um novo cotidiano de vida. Foi assim que a Psicologia surgiu no seio de uma sociedade em mudança, para responder às novas demandas sociais e econômicas tornando-se, ao longo dos anos, uma importante ferramenta de manutenção das relações de produção e reprodução da vida e a Educação passa a ser uma de suas principais vias.

Embora a Psicologia no Brasil, mesmo antes de sua regulamentação, tenha se difundido no interior dos cursos de formação de professores (que precisariam conhecer sobre desenvolvimento infantil e suas patologias para dar aulas para crianças e jovens), com o passar do tempo, ela se populariza como uma profissão de acolhimento àqueles com sofrimento psíquico, seja no sentido amplo ou restrito. Isto, apesar das evidencias históricas de que um dos primeiros espaços de 
interlocução da Psicologia no Brasil foi o contexto educativo, com a preparação de professores ao ensino elementar e à educação especial (Campos, 1999).

Não por mero acaso, em anos de ditadura civil-militar, a partir de 1964 até o início dos anos 1980, os cursos de Psicologia no Brasil iniciaram sua multiplicação territorial com um perfil focado à formação clínica e ao espaço privado de trabalho profissional. Romper com esse modelo de formação tem sido uma tarefa muito importante que mobiliza diferentes fontes e caminhos, desde o debate junto aos programas de formação, até o convencimento ou a demonstração da evidência de que o/a profissional de Psicologia também tem muito a contribuir no cotidiano das escolas, junto aos professores e mais perto das famílias.

Em 2010, em nosso grupo de pesquisa, retomamos alguns autores importantes para reler a história da Psicologia Escolar no Brasil (Guzzo, Mezzalira, Moreira, Tizzei, \& Silva Neto, 2010) e pensar suas perspectivas. Uma das sínteses que fizemos nesse estudo foi que, distante da realidade concreta, a Psicologia produz um conhecimento que tangencia os verdadeiros problemas da Educação e as experiências cotidianas das crianças nesse contexto. A produção científica da área, embora crescente, está voltada para sustentar a produção de programas de pós-graduação, mais do que à problematização da área com outros setores e produção de subsídios teóricos para a mudança da realidade de crianças e adolescentes que estudam na escola pública. Essa condição nos coloca uma perspectiva para a área, que impõe a necessidade de lutar e resistir ao impacto da ideologia dominante sobre a prática profissional vigente. Como forma de resistir e mudar a formação hegemônica ainda nos marcos da doença mental e formas de tratamento, é preciso estar ao lado de educadores, no cotidiano das escolas e tornar visível o trabalho profissional para a promoção do desenvolvimento das crianças junto aos professores. É preciso formar profissionais com uma leitura crítica da realidade brasileira, não apenas pelos estágios da universidade, mas pela experiência de trabalho cotidiano no campo educativo, a partir da inserção e presença cotidiana no campo.

Muito tem sido publicado sobre a influência da psicologia na educação, sobre suas possibilidades de construção conjunta ao processo educativo, a partir de diferentes abordagens teóricas. Reflexões sobre essas questões aparecem nas publicações, especialmente nos grupo de trabalho da Associação Nacional de Pesquisa e Pós-graduação em Psicologia (DelPrette, 2001, Almeida, 2003), mostrando que o esforço ainda deve ser grande para que se mantenha uma interlocução entre estas duas áreas para favorecer a formação e a prática e que há ainda, em meio a este contexto, muitos obstáculos a serem superados (Marinho-Araújo, 2003; Carvalho, 2002). 
A década de 1980 foi marcada, entre nós, pelo fim da ditadura e o início da abertura democrática. Este período resgatou vários debates sobre o papel do psicólogo em espaços distintos da clínica privada, espaços mais comunitários e coletivizados, e passamos a promover avaliações sobre as consequências do processo político sobre nossa prática e sobre o sistema educacional. Em 1988, alguns encontros foram programados, tanto pelo Sindicato dos Psicólogos, quanto pelo Conselho de Psicologia, para retomar as discussões sobre a atuação do psicólogo. Dentre eles, destaco um encontro entre psicólogos que atuavam em contextos educativos para discutirem sua posição na área da Educação (Leite, Khouri, \& Yassle, 1988).

Neste evento, alguns pontos foram reveladores para a compreensão desta relação: 1) o abandono da dimensão histórica que contrastava com o desenvolvimento científico da Psicologia, especialmente buscando oferecer respostas a inúmeras questões colocadas pelo sistema educativo e dirigidas, sobretudo, às dificuldades de aprendizagem de crianças que frequentavam a escola. Por esta razão, a adoção de um conceito de homem e mundo passou a ser fundamento importante para a análise desta relação; 2) além desta dimensão histórica, a qual estabelece sentidos e valores para o conhecimento psicológico em contextos educativos, as dimensões ética e política do processo educativo revelavam a escola como um espaço marcado por uma relação de dominação e submissão, além de funcionar como um mecanismo poderoso de exclusão e vitimização da criança, em que prevalece um sentimento intenso de inferioridade e desvalorização, sem possibilidades ou esperanças, tanto nas crianças como em suas famílias; 3 ) tudo isto, aliado a uma formação profissional comprometida com o ensino de técnicas e métodos, descontextualizadas e incapazes de perceber de forma crítica e realista o que circunda a escola, fez da psicologia um campo de conhecimento legitimador da exclusão. Este marco, de quase 30 anos atrás, continua muito atual nos dias de hoje, provocando em nós uma inquietação de que temos marcado passos na história, sem avanços ou nos acomodamos, ou nos deixamos vencer, ou ainda desistimos de valores que sempre defendemos.

Na década de 1990, as reflexões se aprofundam revelando dimensões políticas e ideológicas envolvidas neste debate, mas poucas mudanças ocorrem no contexto prático. Sob o pretexto da "neutralidade científica" a produção de conhecimento e a sua relação com a prática continuam mantendo a distância entre a ciência e a realidade. No entanto, alguns pesquisadores apresentam um pensamento divergente. O trabalho de Maria Helena Patto, ao abordar a relação entre psicologia e educação, foi incisivo ao apontar o papel desempenhado pela primeira na sustentação da ideologia dominante: "Entre as ciências que na era do capital participaram do ilusionismo que escondeu as desigualdades sociais, historicamente 
determinadas, sob o véu de supostas desigualdades pessoais, biologicamente determinadas, a psicologia certamente ocupou posição de destaque" (Patto, 1991, p.36). Ainda, segundo esta autora, questões sobre ajustamento, normalidade, diferenças individuais, identificação daqueles que são aptos e não aptos centrando suas investigações no indivíduo ou nas relações, entendidas como entidades a-históricas, têm receptividade em uma sociedade regida por teses liberais e uma visão funcionalista da vida social (Patto, 1991).

\section{A distância do contexto escolar - o abandono da perspectiva do desenvolvimento - a Psicologia e o enfoque na doença}

A Psicologia brasileira, depois da regulamentação da profissão e da organização dos cursos de formação profissional, constituiu-se a partir de um movimento dominante de compreensão do ser humano a partir de si mesmo e, neste movimento endógeno, distancia-se da realidade e, portanto, da compreensão da essência humana -servindo à ordem estabelecida- e, principalmente, da relação indivíduosociedade.

As sociedades não são iguais. É preciso entender o impacto das economias na formação social. Os países do hemisfério sul, por exemplo, são constituídos por uma grande maioria de pobres, submetidos, colonizados, que vivem com alto índice de desigualdade social. Países de muitos analfabetos, com um sistema educacional excludente, que institucionaliza a violência, que discrimina e submete milhares de estudantes a relações de dominação e opressão.

Um modo não hegemônico de pensar a Psicologia e a Educação, oferece-nos a possibilidade de reconhecer os limites que ambas possuem, tanto como um corpo de conhecimento quanto como prática profissional, para propiciar a transformação da sociedade. Em outras palavras, nem a Psicologia, nem a Educação, são capazes de mudar a ordem social se pensadas a partir do indivíduo, a partir de si próprias. É preciso romper com os limites impostos pela ordem social em que estas duas áreas se encontram imersas.

Como nos faz pensar Paulo Freire,

se compreendermos a natureza limitada e vinculada da educação, se compreendermos como a educação formal se relaciona com a sociedade global, sem ser apenas a reprodutora da ideologia dominante, e sem ser, também, a principal alavanca da transformação; se compreendermos desse modo nossa prática educacional, evitaremos, então, um certo otimismo ingênuo que pode levar-nos, no futuro, a um 
terrível pessimismo (Freire \& Shor, 1987, p. 158, grifos nossos).

Buscando uma justificativa para o distanciamento da Psicologia da escola pública brasileira, pode-se apontar exatamente o caminho assumido pela área desde sua fundação no Brasil, considerando o efeito que o corpo de conhecimento produzido e sua aplicação têm exercido sobre as práticas pedagógicas e sobre os processos educativos em geral.

A principal resistência de educadores à presença de psicólogos nas escolas advém especialmente, de como este profissional atua sob o modelo hegemônico. Hoje, diante das circunstâncias de um sistema que falha, que discrimina e que procura manter o status quo, resta aos professores desejarem distância daqueles psicólogos que procuram refletir o fracasso da escola sob outras perspectivas. Formados para reproduzir a ordem estabelecida, os profissionais de psicologia, tanto quanto os de educação, acabam mantendo em sua prática uma dinâmica que não analisa e propõe mudanças, a partir de uma perspectiva crítica.

Referindo-se aos profissionais de psicologia, Marvakis (2013) afirma a necessidade de modificara maneira como esses profissionais têm sido formados, pois, ao apenas aprenderem uma atuação técnica distanciam-se da realidade e das necessidades daqueles com quem atuam. Com isso, o corpo de conhecimento psicológico produzido e disponível e a forma de atuação acrítica e despolitizada dos profissionais não têm propiciado condições para uma busca consistente de soluções para os problemas sociais gerados em contextos educacionais. Há dificuldades em se sustentar mudanças para a formação profissional, tanto do psicólogo quanto do educador, para além de propostas curriculares inovadoras que não saem do papel. Além disso, alguns programas de pós-graduação e grupos de pesquisa, tanto em Educação quanto em Psicologia, mantêm pouca articulação entre si, trazendo, como consequência, uma fragmentação na maneira de se discutir esta questão, que enfraquece a posição crítica e as possibilidades de mudança na realidade.

\section{As iniciativas de retomada desse campo para a Psicologia - organizando a categoria, aperfeiçoando a formação}

Maluf (2003) refletiu sobre diretrizes que orientam a formação e a atuação do profissional de psicologia em contextos educativos, também considerando que a produção na área da Psicologia Escolar e na Psicologia da Educação é ampla, extensa e variada, porém de disseminação restrita e limitada. Com discussões recentes sobre a 
formação do psicólogo, iniciamos uma nova década com pouca mudança substancial na relação entre psicologia e educação.

A crise do sistema educacional não é isolada da sociedade. Focalizar este problema como fenômeno local ou individual impede a compreensão da realidade e sua transformação. Trata-se de "um novo trato" às questões sociais, como bem nos mostra Montaño $(2002,2002 a)$. Para este autor, este "novo trato" se caracteriza por um conjunto de falsas soluções para os problemas sociais que deflagram um movimento de descentralização e privatização dos serviços públicos, sob o fundamento de que o "Bem Estar Social" é de responsabilidade do setor privado - famílias, entidades religiosas e filantrópicas, comunidades, organizações não governamentais -, "parceiros" do estado no exercício de suas funções.

As teses neoliberais, que dão sustentação à sociedade capitalista, também definem o sistema educativo, pois "a estrutura do conhecimento oficial é também a estrutura da autoridade social" (Freire \& Shor, 1987, p. 21) e elas devem estar de acordo com o perfil de pessoas necessário à reprodução capitalista. Por esta razão, é preciso reconhecer os limites da educação na proposta de transformação social, especialmente se este processo estiver nas mãos da iniciativa privada, ou for negligenciado pelo Estado. É preciso dar importância ao ato do conhecimento como uma forma de desvelar a realidade e, assim, propiciar o envolvimento de todos em uma perspectiva crítica sobre a escola, sobre a sociedade com vistas à transformação, à mudança social. A autonomia, portanto, é construída pela possibilidade de se desenvolver o pensamento crítico. Neste processo, a psicologia tem importante papel: como seres conscientes, podemos reconhecer o quanto estamos submetidos e condicionados pela ideologia dominante. Para isso, é preciso que aprendamos a ser livres, conhecendo, por princípio, nossa falta de liberdade. O processo de conscientização torna possível, portanto, a libertação. E este processo leva-nos a superar condições de vida, as quais desejamos que sejam transformadas.

\section{A perspectiva crítica em ação - diferentes frentes nacionalizando e internacionalizando ações - os grandes desafios}

A perspectiva crítica pode ser considerada como aquela que rompe com o modelo hegemônico da Psicologia e se funda em uma análise política da realidade. Assim, para fins desse trabalho recuperamos alguns elementos da Psicologia da Libertação proposta por Ignácio Martin-Baró e da Educação Emancipatória de Paulo Freire, dois corpos de conhecimento que têm propiciado um sentido renovador à discussão desta relação e alguns de seus principais condicionantes. 
Embora muito se tenha consolidado de produção nessas duas áreas, estas experiências pouco se disseminam nos espaços educativos regulares. Há um percurso quase sempre usual neste processo do trabalho científico: as experiências ficam nas universidades, nos laboratórios, gerando publicações científicas que têm pouco ou nenhum impacto na formulação e implementação de transformações na prática pedagógica, o que traz à reflexão a ideia de um projeto de sociedade que se mantém pela reprodução ideológica em diferentes segmentos.

A necessidade, cada vez mais premente, de construção da Psicologia Escolar Brasileira, parte do desocultamento da ideologia dominante, que constitui a principal função de um "currículo libertador" entendido aqui como um conjunto de experiências e projetos educativos capazes de levar estudantes e professores à crítica da realidade (Freire \& Shor, 1987). Isto, hoje, tem sido considerado como ameaçador. Assim, podemos fazer com que nossas transformações sejam direcionadas ao processo de revolucionar a constituição do sujeito pela modificação do contexto onde ele vive, das relações sociais históricas que o constituem. Sem a pretensão de esgotar este assunto, a ideia desta reflexão tem como fundamento propiciar uma oportunidade de resgatar a atualidade, tanto de Paulo Freire como de Ignácio Martín-Baró, para entender por onde temos caminhado e por onde precisamos caminhar. Um movimento que temos produzido sobretudo para discutir e avaliar o papel do Psicólogo no contexto educativo.

Se educação é um ato político (Freire, 2000), a relação entre Psicologia e Educação deve, também, considerar sua dimensão política. E, sob este prisma, é um processo de experiência humana com profundas consequências sociais. Educação não pode ser reduzida a um método mecânico de instrução, nem aprendizagem a um montante de informações memorizadas. Educação é um processo em que se pode propiciar o pensamento crítico sobre questões da vida e da sociedade.

Importante considerar que a construção desta relação passa por uma pedagogia consequente; por isso, torna-se importante a tomada de posição sobre a educação que desejamos - aquela que prepara estudantes para uma alienação política? Ou aquela que confronta problemas de maneira crítica, encorajando-os à curiosidade sobre o conhecimento e sobre o mundo, fazendo-os assumir escolhas, tomarem decisões?

A compreensão de que a Educação é um processo importante na formação de sujeito histórico faz-nos assumir que, enquanto processo, pode contribuir tanto para a emancipação quanto para a submissão aos valores e ao funcionamento da sociedade. Esta questão aproxima a Psicologia e a Educação e atribui a este processo um caráter político. Para Freire e Horton (2003) nenhuma reflexão 
sobre educação pode ficar distante das questões relacionadas ao poder, à economia, à justiça, à igualdade, à liberdade e à ética da organização social fundada no direito à vida, sem a exploração de uns sobre os outros, deixando muito claro que o processo de educação nessa perspectiva contrapõe-se à estrutura social vigente.

A partir de uma análise da obra de Freire (1973, 1979, 2000; Freire \& Macedo, 1994) e refletindo sobre a importância deste processo, podese concluir da possibilidade de tornar a Educação um processo que emancipa e não domestica, que visa à crítica, à autonomia, e que pode romper com a reprodução da ideologia dominante permitindo ao indivíduo viver sua história de maneira realista e consequente. Nessa direção, quanto mais a consciência crítica é desenvolvida pelo processo educativo, mais a participação se torna possível nas ações sociais de transformação e, por meio da participação, é possível a mobilização no combate às relações de exploração e injustiças e na busca de condições materiais que superem a sociedade capitalista. Uma superação que se forja no âmbito das relações sociais.

Tal como escreveu Marx em sua sexta tese sobre Feuerbach, "a essência humana não é algo abstrato, interior a cada indivíduo isolado. É, em sua realidade, o conjunto das relações sociais" (Marx, n.d., p.209). Assim sendo, a psicologia não pode procurar compreender o psíquico somente nos indivíduos, pois a chave de sua compreensão não está nele (Sève, 1979). Esta afirmação é de grande importância para se compreender a relação entre Psicologia e Educação, entre indivíduo e sociedade, entre o coletivo e o individual na constituição das pessoas e de seus grupos sociais. A psicologia, portanto, tal como discute Prilleltensky (1994), tem repercussões morais e políticas na vida social. Não há como negá-las. Estas repercussões afetam a vida, tanto ao nível individual como coletivo e, por isso, é importante ter em mente a relação entre a teoria psicológica e o estado atual da sociedade.

Ao compreender a constituição humana a partir de uma perspectiva histórica, tornam-se importantes as análises sobre como se processam as relações diante das condições em que vivem as pessoas - suas necessidades, sua liberdade, seu bem-estar, 0 trabalho e sua sobrevivência. Isto leva a uma posição crítica em relação ao conhecimento psicológico e sua prática, sobretudo aqueles que focalizam o indivíduo descolado de seu mundo e de seus processos relacionais.

A Psicologia dominante não fornece elementos para uma análise histórica e social do homem. Pelo contrário, favorece a representação do homem como independente da ideologia e compreende as funções psíquicas como situadas à parte. Para Ratner (1971), o indivíduo precisa do contexto para formular o conteúdo de seus pensamentos e ações, para gerar uma gama de possibilidades de pensar e agir, dentre as quais ele pode escolher. 
Como perguntam Marx e Engels (2002) “será preciso grande inteligência para compreender que, ao mudarem as relações de vida dos homens, as suas relações sociais, a sua existência social, mudam também as suas representações, as suas concepções e conceitos; numa palavra, muda a sua consciência?" (p. 56-57). Neste sentido, vale considerar que o indivíduo não existe sem a realidade que o cerca, e, se a realidade muda, mudam os indivíduos, muda sua consciência sobre o mundo.

A compreensão, portanto, da estrutura e desenvolvimento da personalidade humana deve ser tomada no conjunto de suas relações, o que se traduz, como apresenta Sève (1979), no sentido da atividade psicológica e seu caráter histórico e social. Para este autor, a ideologia burguesa naturaliza a atividade psicológica e, neste sentido, a Psicologia, a serviço desta ideologia, distancia-se da realidade. Para discernir os fundamentos de uma psicologia historicamente concreta e revolucionária, a vida real das pessoas deve ser entendida a partir da interiorização de suas relações políticas e sociais. Esta tese reforça a importância de que espaços de relações autoritárias e opressoras favorecem a reprodução da violência e opressão. Por isso, Maar (1989) afirma que a forma que construímos nossas relações sociais e nossa vida, mesmo se for no nível mais íntimo, também é uma ação política, e, para Parker (2009) essa ação política pode ser entendida tanto no conceito amplo quanto no restrito. Se a Psicologia está a serviço da ideologia dominante, é preciso que possamos trabalhar para romper com o discurso político e social dominante, para que possa se emancipar, como uma ciência voltada aos interesses da maioria dominada, como propõe Ignácio Martín-Baró (Martín-Baró, 1998).

A psicologia da libertação tem como propósito mudar a realidade fundada em uma ética que, segundo Dobles (2005), significa um princípio de manutenção da vida humana, em sua corporeidade, em suas características específicas e em comunidade, sem deixar de lado fatores estruturais e de ordem social que condicionam situações de opressão, desigualdade e heteronomia.

Para Martín-Baró (1998), se a singularidade do homem consiste na vida que ele constrói historicamente por meio de suas relações sociais, então a saúde psicológica constitui-se como um problema principal, pois não se trata, meramente, de satisfação das necessidades individuais, mas, fundamentalmente, uma questão de caráter relacional, ou seja, uma dinâmica que define as possibilidades de humanização para membros de cada sociedade e grupo. A Psicologia da Libertação, tal como discute Lykes (2000), significa assumir posições políticas, uma escolha ética germinada pela verdade da razão e da compaixão e não é um viés ou interferência na produção de conhecimento. Evidentemente, a posição assumida por Martín-Baró, suas pesquisas e seu assassinato em 16 de novembro 
de 1989, são consequências desse seu envolvimento na busca pela mudança social. Psicologia da Libertação, tal como a caracterizou Martín-Baró (1996), é um chamado para a ação, um desafio para desenvolver a prática e a teoria tendo como base a experiência das comunidades com quem o psicólogo trabalha. Situações limites, como as denomina o autor, aquelas situações de extrema dificuldade, opressão, sofrimento, podem se tornar condições para 0 desenvolvimento de uma consciência libertadora, crítica e emancipatória.

\section{E a luta continua...}

Considerando que a Educação pode se constituir em um processo para a promoção do desenvolvimento de sujeitos autônomos e conscientes sobre que caminhos devem buscar para transformar suas vidas, a relação entre Psicologia e Educação, passa a assumir uma perspectiva macrossocial quando se torna uma política pública para qualificar a educação pública. Esse processo se efetiva quando se toma consciência da importância do psicólogo no contexto educativo Martín-Baró (1996) defende que a conscientização precisa ser parte do horizonte do psicólogo, uma atividade necessária para a desideologização, ou seja, de quando as pessoas conhecem e agem no mundo, sendo agentes de sua própria história (Freire, 1980). Se entendermos o processo de tomada de consciência como um processo contínuo, que pressupõe uma luta constante, internaexterna, individual-coletiva, temos ainda algumas limitações cotidianas a superar, a fim de mudarmos a realidade em que vivemos.

Como Sarason (1983) propôs, a Psicologia deve se movimentar para um campo de conhecimento e atuação que enfatize análises e intervenções de caráter social, mudando a prática e o referencial teórico que a tem sustentado. Neste campo de conhecimento e atuação, a escola e a comunidade se integram para o planejamento, avaliação e desenvolvimento de ações conjuntas. É diante desta perspectiva que a escola, como instituição social, pode se assumir como reprodutivista ou revolucionária, na medida em que atribui 0 fracasso escolar ao indivíduo ou ao sistema em que ele vive.

Durante os últimos 25 anos, profissionais e pesquisadores brasileiros envolvidos nessa luta têm conseguido consolidar algumas ações importantes para envolver outras psicólogas e psicólogos em torno dessa bandeira - Psicologia NA escola! São distintas ações nesse tempo visando reestabelecer os vínculos entre Psicologia e Educação, sob um cenário de convivência participativa olhando ambas as áreas para um horizonte de emancipação por meio de um processo educativo. Podemos considerar, nesse âmbito, a criação da 
Associação Brasileira de Psicologia Escolar e Educacional (ABRAPEE) e toda a movimentação política em torno de uma legislação que assegure o trabalho profissional nas escolas públicas. São frentes que nos impelem a organizar a área e recorrer a um perfil de formação diferente do atual para a Psicologia.

A construção de uma nova ordem social em que homens e mulheres se relacionem sob a égide da igualdade e da justiça é uma proposta que demanda esforço e persistência, sobretudo com a participação da Psicologia Escolar, já que é, também, na escola que acontece o desenvolvimento integral de crianças e adolescentes. Participação que exige revisões constantes e propostas disseminadas criticamente. E é neste momento que se torna necessário enfatizar a importância de ações para romper com uma psicologia que mantém o status quo e construir um corpo de conhecimento que dê conta de entender e agir na realidade em que vivemos, tomando como referência aqueles que, como Ignácio Martín-Baró e Paulo Freire, nos mostram caminhos, sobretudo para a caminhada na América Latina e no Brasil.

\section{Referências}

Almeida, S. F. C. (Org.). (2003). Psicologia Escolar: ética e competências na formação e atuação profissional. Campinas: Alínea.

Brasil. (2015). Lei Darcy Ribeiro (1996). LDB Nacional: Lei de diretrizes e bases da educação nacional: Lei no 9.394, de 20 de dezembro de 1996 (11a ed., Série Legislação, n. 159). Brasília: Câmara dos Deputados, Edições Câmara.

Campos, R. H. F. (1999). A psicologia em Genebra e os movimentos em defesa dos direitos das crianças (1920-1940): Conexões epistemológicas. In M. C. Guedes \& R. H. F. Campos, Estudos em história da psicologia (pp. 67-94). São Paulo: EDUC.

Carvalho, D. C. (2002). A psicologia frente a educação e o trabalho docente. Psicologia em Estudo, 7(1), 51-60. doi: 10.1590/S1413-73722002000100008

Del Prette, Z. A. P. (2001). Psicologia escolar e educacional, saúde e qualidade de vida: Explorando fronteiras. Campinas: Alínea.

Dobles, I. (2005, Fevereiro 22). Psicología de la Liberación: condiciones de posibilidad. Palestra proferida in Aula Inaugural da Pós-Graduação em Psicología. Campinas, SP: Mimeo/PUCCampinas.

Freire, P. (1973). Uma educação para a liberdade. Porto: Antonio Abreu.

Freire, P. (1979). Ação cultural para a liberdade e outros escritos. Rio de Janeiro: Paz e Terra. 
Freire, P. (1980). Conscientização: Teoria e Prática da Libertação, uma introdução ao pensamento de Paulo Freire (3a ed.). São Paulo: Editora Moraes.

Freire, P. (1999). Educação como prática da liberdade. Rio de Janeiro: Paz e Terra.

Freire, P. (2000). Pedagogia do oprimido (17a ed.). Rio de Janeiro: Paz e Terra.

Freire, P., \& Shor, I. (1987). Medo e ousadia: O cotidiano do professor. Rio de Janeiro: Paz e Terra.

Freire, P., \& Macedo, D. (1994). Alfabetização: Leitura do mundo, leitura da palavra. São Paulo: Paz e Terra.

Freire, P., \& Horton, M. (2003). O caminho se faz caminhando: Conversas sobre educação e mudança social. Petrópolis: Vozes.

Guzzo, R. S. L., \& Almeida, L. (1992). A relação psicologia e educação: perspectiva histórica do seu âmbito e evolução. Estudos de Psicologia, 9(3), 117-131.

Guzzo, R. S. L., Mezzalira, A. S. C., Moreira, A. P. G., Tizzei, R.P., \& Silva Neto, W. M. F. (2010). Psicologia e Educação no Brasil: uma visão da história e possibilidades nessa relação. Psicologia: Teoria e Pesquisa, 26(n. esp.), 131-141. doi:10.1590/S010237722010000500012

Leite, S. A. S., Khouri, I. G., \& Yassle, E. (1988). Anais do I Encontro de psicólogos que atuam em contextos educativos. São Paulo: Sindicato dos Psicólogos de São Paulo.

Lykes, M. B. (2000). Possible contributions of a psychology of liberation: Whither health and human rights? Journal of Health Psychology, 5(3), 383-397. doi: 10.1177/135910530000500312

Maluf, M. R. (2003). Psicologia escolar: Reafirmando uma nova formação e atuação profissional. In O. H. Yamamoto, \& V. V. Gouveia (Orgs.), Construindo a psicologia brasileira: Desafios da ciência e prática psicológica. São Paulo: Casa do Psicólogo.

Maar, W. L. (1989). O que é política (Coleção Primeiros Passos, n.54). São Paulo: Brasiliense.

Marinho-Araújo, C. M.(2003). Psicologia escolar e o desenvolvimento de competências: uma opção para a capacitação continuada (Tese de Doutorado não publicada). Universidade Nacional de Brasília, Brasília.

Martín-Baró, I. (1996). The role of psychologist (A. Aron \& S. Corne, Trad.). In A. Aron \& S. Corne (Eds.), Writings for a liberation psychology (pp. 33-46). Londres: Harvard University Press.

Martín-Baró, I. (1998). Hacia una psicología de la liberación. In A. Blanco (Org.), Psicología de la liberación (pp. 283-302). Madrid: Trotta.

Marvakis, A. (2013). Vignette 2: Historicity of societal organization historicity of critical psychology. Annual Review of Critical Psychology, 10, 10-12. 
Marx, K., \& Engels, F. (1848/2002). Manifesto comunista (Á. Pina, Trad.). In O. Coggiola (Org.), Manifesto comunista (pp. 37-69). São Paulo: Boitempo.

Marx, K. (n.d.). Teses sobre Feuerbach. In K. Marx, \& F. Engels (Orgs.), Obras escolhidas (Vol. 3, pp. 208-210). São Paulo: Alfa-Ômega.

Montaño, C. (2002). Terceiro setor e questão social: Crítica ao padrão emergente de intervenção social. São Paulo: Cortez.

Montaño, C. (2002a). O projeto neoliberal de resposta à "questão social" e a funcionalidade do "terceiro setor". Lutas Sociais, 8, 53-64.

Recuperado http://www4.pucsp.br/neils/downloads/v8_carlos_montano.pdf

Parker, I. (2007). Revolution in psychology: Alienation to emancipation. London: Pluto Press.

Parker, I. (2009). Critical Psychology and Revolutionary Marxism. Theory \& Psychology, 19(1), 71-92. doi: $10.1177 / 0959354308101420$

Patto, M. H. S. (1991). A produção do fracasso escolar: Histórias de submissão e rebeldia. São Paulo: T. A. Queiroz.

Prilleltensky, I. (1994). The morals and politics of psychology: Psychological discourse and the status quo. Albany: State University of New York Press.

Ratner, C. (1971). Principles of dialectical psychology. Telos, 9, 83109.

Sarason, S. B. (1983). School Psychology: an autobiographical fragment. Journal of School Psychology, 21(4), 285-295.

Sève, L. (1979). Marxismo e a teoria da personalidade (Vol. 1, E. L. Godinho, Trad.). Lisboa: Horizonte.

\section{Endereço para correspondência \\ Raquel Souza Lobo Guzzo}

PUC-Campinas - Campus II

Avenida John Boyd Dunlop, s/nº, Jd. Ipaussurama, CEP 13060-904, Campinas - SP, Brasil

Endereço eletrônico: rslguzzo@gmail.com

\section{Flávia de Mendonça Ribeiro}

PUC-Campinas - Campus II

Avenida John Boyd Dunlop, s/nº, Jd. Ipaussurama, CEP 13060-904, Campinas - SP, Brasil

Endereço eletrônico: ribeiro.m.flavia@gmail.com

Recebido em: 01/10/2018

Reformulado em: 13/04/2019

Aceito em: 14/04/2019 
Raquel Souza Lobo Guzzo, Flávia de Mendonça Ribeiro

\section{Notas}

* Professora Doutora da Pós-graduação em Psicologia pela Pontifícia Universidade Católica de Campinas.

** Doutora em Psicologia pela Pontifícia Universidade Católica de Campinas.

${ }^{1}$ Lei no 8.069, de 13 de julho de 1990.

Este artigo de revista Estudos e Pesquisas em Psicologia é licenciado sob uma Licença Creative Commons Atribuição-Não Comercial 3.0 Não Adaptada. 